\title{
BIOMECHANICAL SUBSTANTIATION FOR EXTERNAL FIXATION OF THE PELVIS USING RODS WITH DIFFERENT THREAD HANDS
}

\author{
Istomin A.G. ${ }^{1}$, Kovaliov S.I. ${ }^{2}$, Zhuravliov V.B. ${ }^{1}$, Istomin D.A. ${ }^{1}$, Karpinskiy M.Yu. ${ }^{3}$ \\ ${ }^{1}$ Kharkiv National Medical University \\ ${ }^{2}$ Municipal Noncommercial Enterprise "City Clinical Hospital No. 17 \\ of Kharkiv City Council" \\ ${ }^{3}$ State Institution "Sytenko Institute of Spine and Joint Pathology of the National Academy \\ of Medical Sciences of Ukraine \\ https://doi.org/10.35339/ic.8.1.37-46
}

\begin{abstract}
Background. External fixation devices (EFD) have found wide application in pelvic fractures treating, but it is not always that strength characteristics of these devices make it possible to realize early rehabilitation. Objective: the biomechanical justification for external pelvic osteosynthesis with use of rods having different thread hands on the basis of analysis of the stress-strain state (SSS) of the "EFD - pelvis" system and an experimental study of the strength of threaded connections of different rods and the pelvic bone under the effect of alternate cyclic loads. Materials and Methods. Was analyzed the SSS of the "EFD - pelvis" system verified in an experimental study of the strength of threaded connections of different rods and the pelvic bone under the effect of alternate cyclic loads. Results: standing on a single basis in the AVF rods with the same thread, there are torques directed in different directions: on the right - clockwise (screwing in), on the left - counterclockwise (screwing out).A change in the thread direction does not lead to change in the moment values, but directions of the action of the moments of force for the left rod will correspond to the direction of its screwing both in the left- and right-sided one-support position. Conclusions: Bar-connected rods with a differently directed thread create a reciprocally interlocking structure, which counteracts self-unscrewing. Such a structure significantly increases the strength of connection of an EFD with the pelvic bone and creates conditions for an effective use of the early rehabilitation of patients with pelvic fractures.
\end{abstract}

Key words: pelvis, stress-strain state, external fixation, experimental study.

\section{Introduction}

The results of medical rehabilitation of patients with consequences of unstable pelvic fractures (UPF) depend upon many factors, among which the strength of fixation of the fragments that makes possible early recovery of the staticodynamic function of the lower girdle is particularly important,

External fixation rod devices are widely used in treating fresh UPF and their consequences,

Corresponding Author:

Andriy Istomin, MD, PhD, Professor,

Head of the Department of physical rehabilitation, sports medicine with a course of physical

education and health, Kharkiv National

Medical University, Kharkiv, Ukraine.

E-mail: ah.istomin@knmu.edu.ua but it is not always that strength characteristics of these devices make it possible to realize modern tendencies in medical rehabilitation, which call for early verticalization of the patients and use of constant passive movement and application of electromechanical splints. This is explained by the fact that in patients with UPF, who have underwent external osteosynthesis with a rod device, both axial load and repeated cycles of hip flexion and extension reduce the strength of rod fixation in the iliac bone.

In order to improve strength characteristics of the "external fixation device - pelvis" system, experimental studies and mathematical modeling with use of the finite element method (FEM) have been conducted [1-4]. Recently, assessment of the stress-strain state (SSS) of biomechanical systems with FEM has become widely used [5- 
8]; herewith good prospects of this method in modeling both internal and external pelvic fixation are indicated [9-11].

\section{Purpose, subjects and methods:}

2.1. The purpose of the present study was to substantiate biomechanically external pelvic osteosynthesis with the use of rods having different thread hands on the basis of analysis of the stress-strain state of the "external fixation device - pelvis" system and an experimental study of the strength of threaded connections of different rods and the pelvic bone under the effect of alternate cyclic loads.

\subsection{Subjects \& Methods}

At the first stage of this study we analyzed the stress-strain state of the "external fixation device - pelvis" system on a finite element mathematical model, which was built on the basis of tomographic sections of the pelvic bones, drawn through $0.5-1 \mathrm{~cm}$ for irregular zones. Two variants of the calculation model were built (Fig. 1). The first one was intact. The second one was the model of a rotationally unstable pelvic fracture

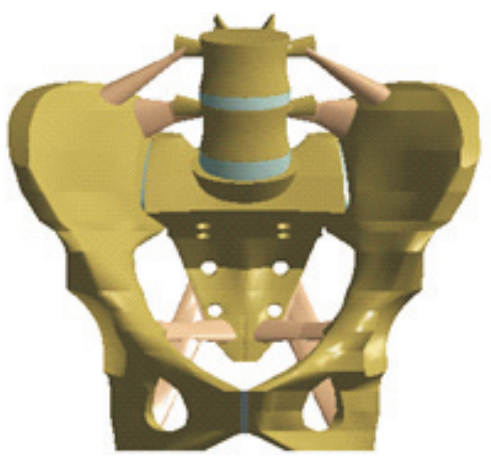

$a$ homogeneous and isotropic. We used the data, which are most commonly found in literature [1214]. The mechanical characteristics of biological tissues are summarized in Table 1.

Table 1

\section{Mechanical characteristics of biological tissues}

\begin{tabular}{|l|c|c|c|}
\hline \multicolumn{1}{|c|}{ Tissue } & E (MPa) & $v$ & Source \\
\hline Cortical bone & 12240 & 0.3 & {$[12]$} \\
\hline Cancellous bone & 380 & 0.3 & {$[12]$} \\
\hline Cartilage & 5.58 & 0.45 & {$[13]$} \\
\hline Ligaments & 330 & 0.4 & {$[14]$} \\
\hline
\end{tabular}

The values of resultant muscle forces and angles of their power for the pelvis were taken in compliance with the data from the study of L. Modenese, A.T.M. Phillips, A.M.J. Bull (2011) [15]. The pattern of loading and fixation of the model is shown in Fig. 2. The body mass, equal to 700 $\mathrm{N}$, was the major load. In one-support standing the applied force value was $540 \mathrm{~N}$ (without including the weight of the weight-bearing extremity).

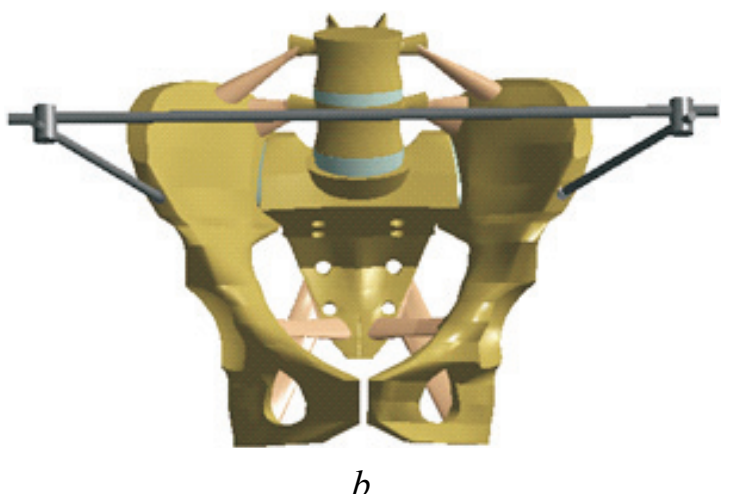

b

Fig. 1. Calculation models: a) intact model; b) model with a fracture of B1 type fixed with EFD

of $\mathrm{B} 1$ type (AO) (rupture of the pubic symphysis and left ventral sacroiliac ligament), fixed with a rod device. The model consisted of 59,713 finite elements (10-noded isoparametric tetrahedrons) and had 111,420 nodes. All contact pairs of model elements, apart from external fixation device (EFD) rods and pelvic bone, were performed by the "bonded" type. The contact pair between the threaded portion of fixing screws and the iliac bone was performed by the "frictional" type with the metal-bone friction coefficient equal to 0.3 . The geometric model was built using the Solid Works program. The calculations were carried out in the ANSYS program.

Previous studies took into consideration different kinds of biological tissues: cortical and cancellous bones, cartilaginous tissue, ligaments. In our study the material was regarded to be

\section{Results \& Discussion}

Analysis of the performed calculation of SSS (Fig. 3) shows that the region of the sacroiliac joint on the weight-bearing side is the most stressed element of the model. The stressed state level in this region reaches to $11.5 \mathrm{MPa}$. In the study by Ding S. et al (2020) [4] the authors received on an intact model in one-support standing the maximum values in the same region equal to $28 \mathrm{MPa}$. It should be emphasized that higher values of the stressed state in the above study resulted from modeling with a higher load, $600 \mathrm{~N}$, as well as from using higher values for the elastic modulus of materials. In the anterior pelvic ring, the most stressed regions are as follows: the superior pubic ramus from the weightbearing side $-4.7 \mathrm{MPa}$, and the anterior acetabular rim from the non-weight-bearing side $-3.7 \mathrm{MPa}$. 


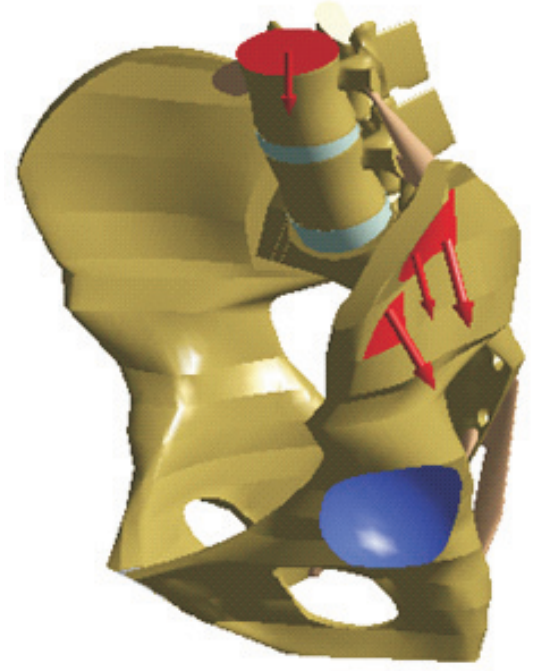

Fig. 2. The pattern of loading and fixation of the model: red color - applied load and muscle forces, blue color - the area of fixation

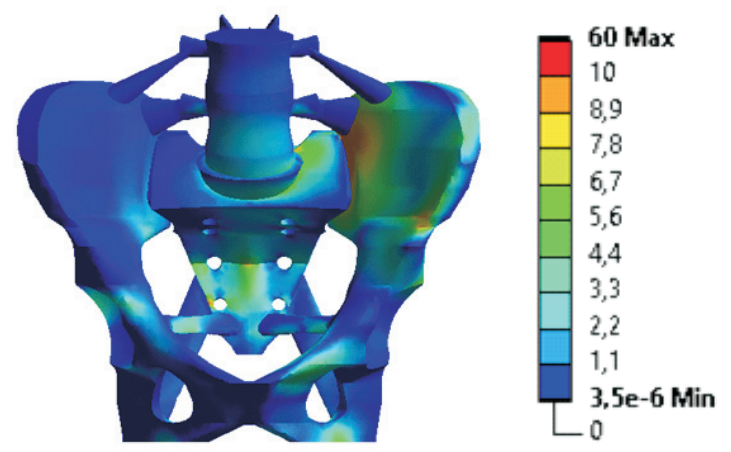

Fig. 3. Von Mises stresses in the intact model

Fig. 4 shows the displacement of the model. With a support from the left leg, displacements of the iliac bone and sacroiliac joint from the nonweight-bearing side do not exceed $0.4 \mathrm{~mm}$.

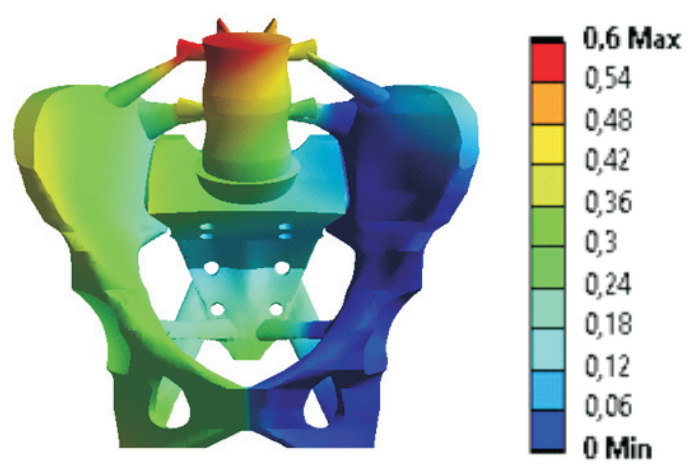

Fig. 4. Displacements of the intact model

Analysis of SSS of the intact pelvis revealed the following facts:

1. The sacroiliac joint from the weight-bearing side, the pubic rami from the weight-bearing side and the anterior acetabular rim from the non- weight-bearing side are the most stressed regions of the model with the stressed state level not exceeding $11.5 \mathrm{MPa}$.

2. The right (non-weight-bearing) pelvic side slightly moves down (not more than by $0.4 \mathrm{~mm}$.

3 . The stressed state level in the bone structure is not critical from the perspective of strength.

The next stage of our study consisted in examination of SSS of the pelvic model with a rotationally unstable pelvic fracture of B1 type and fixation with a rod device in one-support standing. Analysis of the performed calculation (Fig. 5) shows that EFD rods are the most stressed elements of the model. The stressed state level in them does not exceed $60 \mathrm{MPa}$. For bone structures, the most stressed regions are as follows: the sacroiliac joint from the weight-bearing side $-14.1 \mathrm{MPa}(11.5 \mathrm{MPa}$ for the intact model) and the entrance of rods into the bone, where the maximum value of von Mises stresses is $11.9 \mathrm{MPa}$ for the weight-bearing side ( $5 \mathrm{MPa}$ for the intact model) and 8.9 MPa for the nonweight-bearing one ( $0.2 \mathrm{MPa}$ for the intact model).

Fig. 6 demonstrates the distribution of SSS along the passage of EFD rods in the bone in more detail. Our analysis revealed that on the weight-bearing side the stressed state level in the rod was higher and its distribution was more homogeneous along the whole length of the threaded portion. As for the weight-bearing side (Fig. 6a), the stressed state level on the rod-bone border changed within 9.5-11.9 MPa. On the nonweight-bearing side, the stressed state distribution was not homogeneous, a higher level was observed approximately on one-fourth of the threaded portion length of the rod and changes (Fig. 6b) within 3.5-8.9 MPa.

Fig. 7 shows comparison of the deformed and undeformed model (the gray color). With a support from the left leg, the largest displacement is performed by the right node of rod fixation $-4.7 \mathrm{~mm}$.

The above displacement creates a rotary moment of force around EFD rod axes, which acts on the left rod in the counterclockwise direction from a front view (Fig. 8). The performed calculation results in the value of the moment in the node of fixing of the transverse bar and the left rod equal to $4.1 \mathrm{Nm}$. The value of the moment in the right rod in the section of the node of intersection with the transverse bar is less and equals to $0.02 \mathrm{Nm}$. The direction of the moment action corresponds to a clockwise turn from a front view. When the support is changed for the right leg we receive a symmetrical pattern of SSS distribution, and the direction of moments in the nodes of rod fixing is 


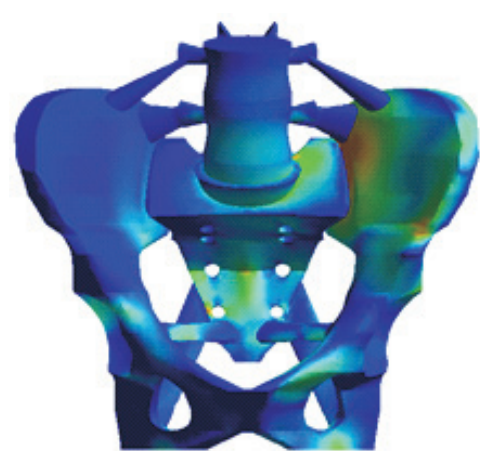

$a$

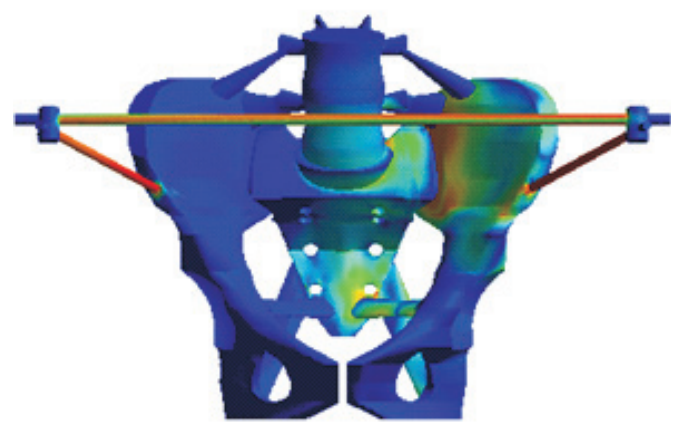

$b$

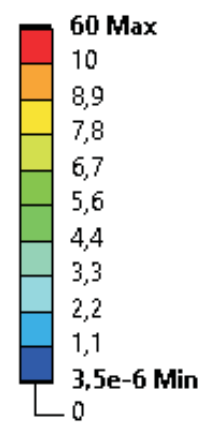

$c$

Fig. 5. Von Mises stresses: a) in the intact model;

b) in the model with a fracture of B1 type fixed with EFD
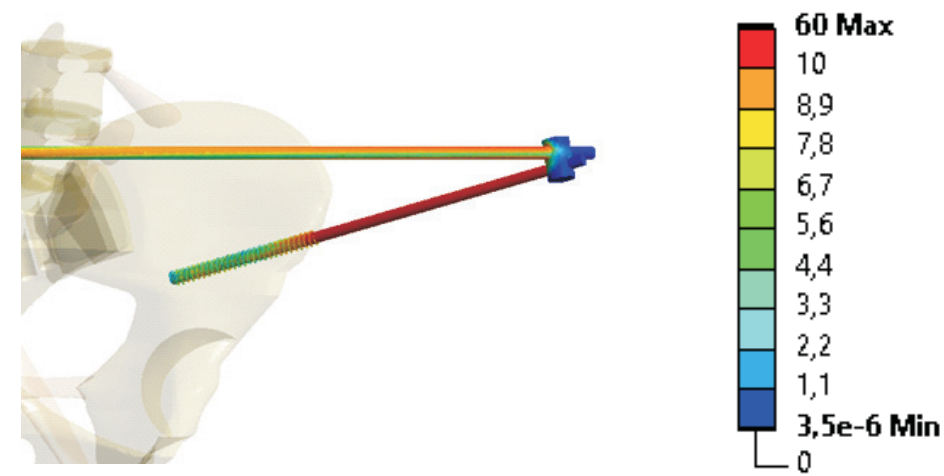

$a$
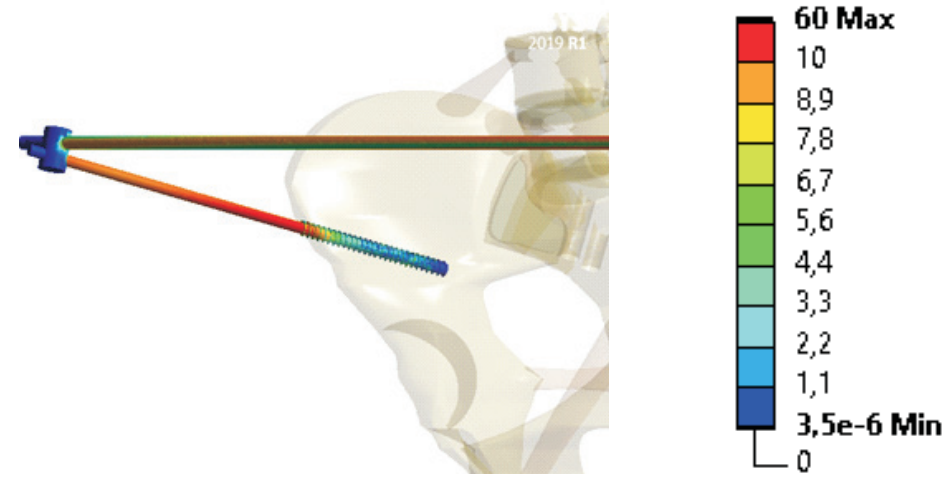

$b$

Fig. 6. Von Mises stresses in section: a) the left rod; b) the right rod

preserved (clockwise for the right screw and counterclockwise for the left one).

Analysis of SSS of the pelvic model with a fracture of B1 type fixed with EFD revealed the following facts:

1. EFD rods are the most stressed elements of the model, the rod from the weight-bearing side of the pelvis being more stressed.

2 . The right (non-weight-bearing) pelvic side slightly moves down thereby creating a moment of force, which acts on the left rod counterclockwise and facilitates unscrewing of the left rod (in case of a right-handed thread).
3. The stressed state level in the bone structure is not critical from the perspective of strength.

The comparative analysis of calculations of SSS demonstrated that one-support standing develops rotary moments with different directions in EFD rods. For the right fixing screw, both in left and right one-support standing, a moment of force was created, which was clockwise and facilitated screwing (strengthening of fixation) of the rod. For the left fixing rod, a moment of force was created, which was counterclockwise and facilitated unscrewing of the rod (destabilization of EFD) both in left and right one-support standing. 

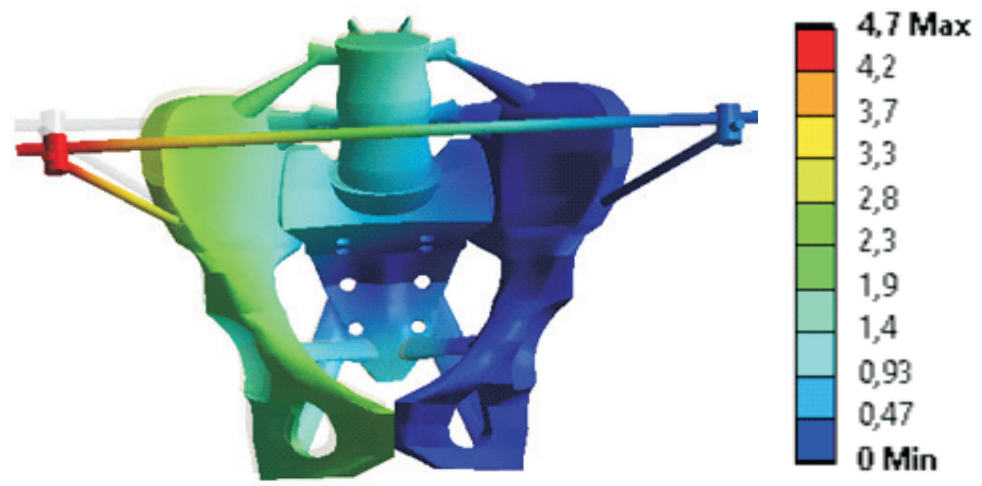

Fig. 7. Displacements of the model

(the scale of deformity is multiplied by 2.5 times for illustration purposes)

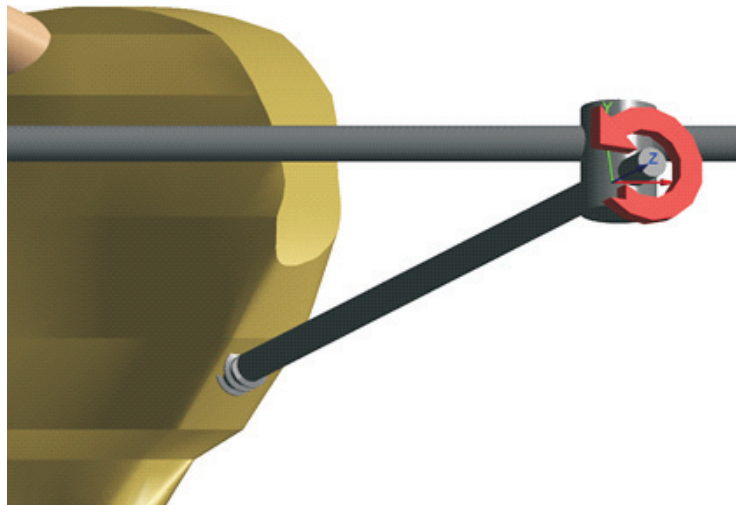

Fig. 8. The direction of the moment in the section of the left EFD rod

Results of the mathematical modeling were verified in an experimental study of the strength of threaded connections of different rods and the pelvic bone under the effect of alternate cyclic loads.

The experimental studies were conducted on the specimens of the pelvic bones of a pig. We used external fixation devices having rods with a cylindrical unidirectional thread and rods, where one had a right-handed thread and the other was with a left-handed thread (Fig. 9).

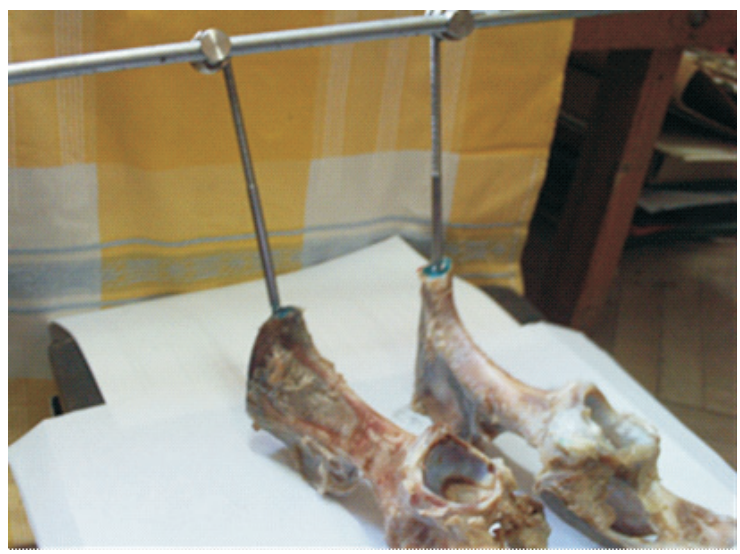

Fig. 9. The experimental model on the testing device
For each type of rods, three preparations were used. Cyclic alternate loads were performed with help of a shaker device (Fig. 10) with vibration frequency of $25 \mathrm{~Hz}$ and amplitude of $2.5 \mathrm{~mm}$ [16].

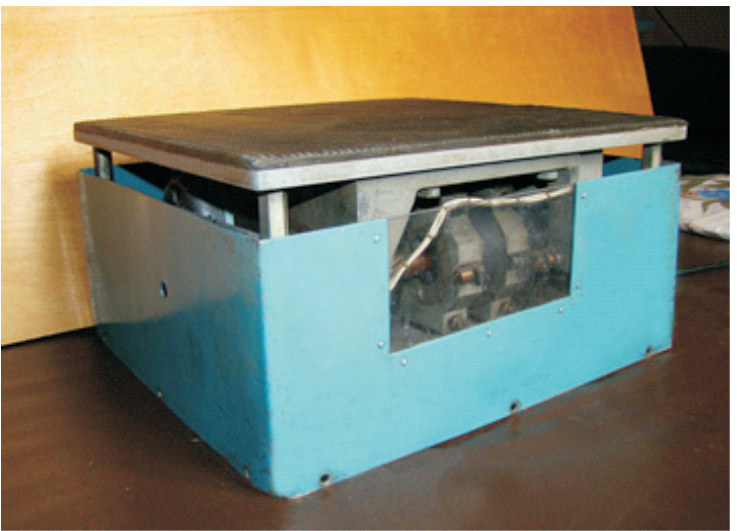

Fig. 10. The shaker device

The vibration lasted for 30 minutes, this duration corresponding to 45,000 gait cycles. Contact places of the rods with the bone were treated with brilliant green.

In the end of the experiment the value of selfunscrewing of the screws from the bone was determined with help of an optical micrometer (Fig. 11).

Besides, the value of the unscrewing moment during screwing of the rod into the bone tissue was experimentally studied. For this purpose we used a rigidly fixed preparation of the hip bone of a pig. With help of a tommy bar the rod was screwed into the mid-diaphysis across its entire width. The scheme of the experiment is shown in Fig. 12.

The length of the lever of action of the unscrewing force in our experiment was:

$1=100 \mathrm{~mm}$.

A photograph of the experiment procedure is presented in Fig. 13.

The unscrewing force was applied to the tommy bar, and its value was measured with help 


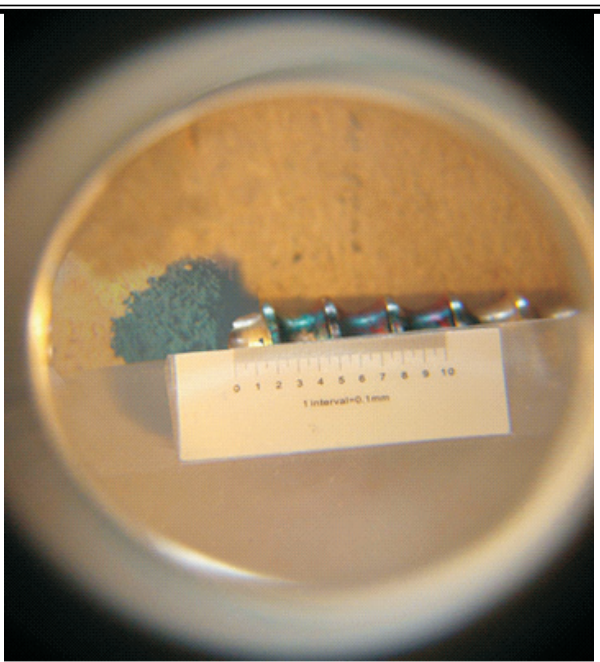

Fig. 11. The view of the specimen under an optic micrometer

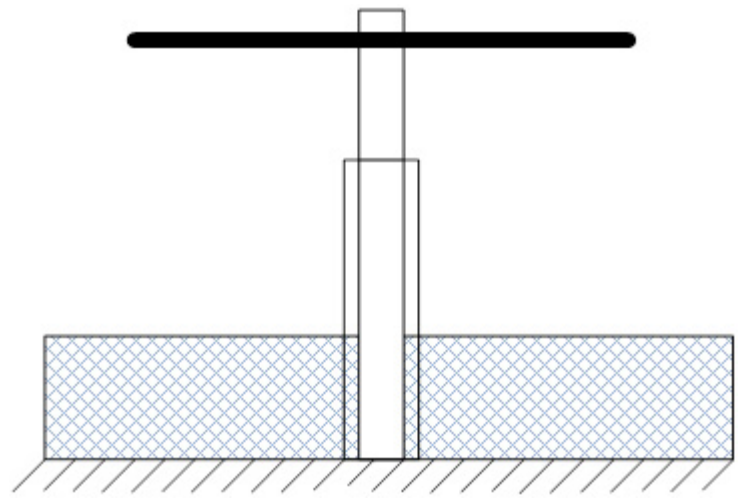

geometrical characteristics of thread and forces in the threaded connection are given in Fig. 15.

According to [17], the moments, which are necessary for unscrewing a threaded connection, can be presented in the form of:

$M_{\text {вгв }}=M_{\text {вигв }} \frac{\left[\tan (\phi+\psi)+f_{T} \frac{d_{c p}}{d_{2}}\right]}{\left[\tan (\phi-\psi)+f_{T} \frac{d_{c p}}{d_{2}}\right]}$

where Munscr, Mscr - the moments, required for unscrewing/screwing a threaded connection;

$\mathrm{fR}$ - friction ratio on the thread edge;

$\mathrm{dm}$ - mean diameter of a contact ring; $\mathrm{d} 2$ - pitch diameter.

Results of our experimental study of the unscrewing moment value for a rod, screwed into

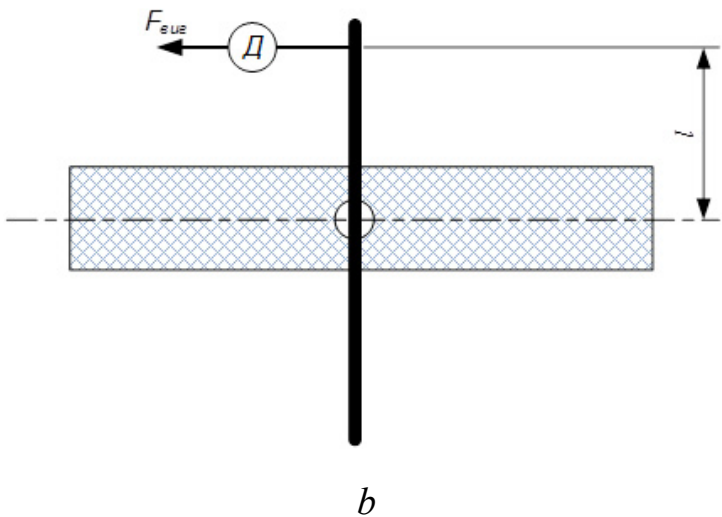

Fig. 12. The scheme of the experiment with unscrewing of the rod:

$a$ - view in the sagittal plane; $b$ - top view ( D - dynamometer; Funscr - force of unscrewing;

1 - length of the lever of action of the unscrewing force)

of a tensometric sensor SBA-100L and a CAS registration device of CI-2001 type (Fig. 14).

The unscrewing moment value was calculated using the formula [16]:

$$
\text { Munscr }=\mathrm{Fl} \text {, }
$$

where $\mathrm{F}$ - value of the unscrewing force;

1 - length of the lever of action of the unscrewing force.

By results of the experiment we calculated the value of the screwing moment [17] and critical values of the amplitude and frequency of vibration, with which a rod can unscrew [18].

The experimental data were subjected to statistical processing. We calculated the mean value $(\mathrm{M})$ and its standard deviation $(\mathrm{SD})$ as well as the minimum and maximum values. Analysis of the findings was performed in a pack for statistical analysis IBM Statistic SPSS 20.0 [19].

In order to understand the alternate cyclic loads on the strength of threaded connections let us use the method of calculations presented in [16]. The the diaphyseal portion of the hip bone of a pig, are shown in Table 2.

According to the results of our experimental study the mean value of the unscrewing moment was $3.3 \pm 0.32 \mathrm{Nm}$. Therefore for calculating we take the mean value:

Munscr = 3,3 Нм.

In compliance with additional data [16] we chose the value of the friction ratio for the metal-bone pair: $\mathrm{fT}=0.3$.

We chose the last parameters according to the design of the rod, engaged in the experiment:

$\mathrm{Dm}=5 \mathrm{~mm}$;

$\mathrm{d} 2=6 \mathrm{~mm}$

$\psi=10^{\circ}$

$\phi=30^{\circ}$;

$\mathrm{P}=3 \mathrm{~mm}$.

If the above values are inserted into the equation (2), the value of the screwing moment of our rod is received:

$\mathrm{M}_{\text {unscr }}=4.9 \mathrm{Nm}$ 


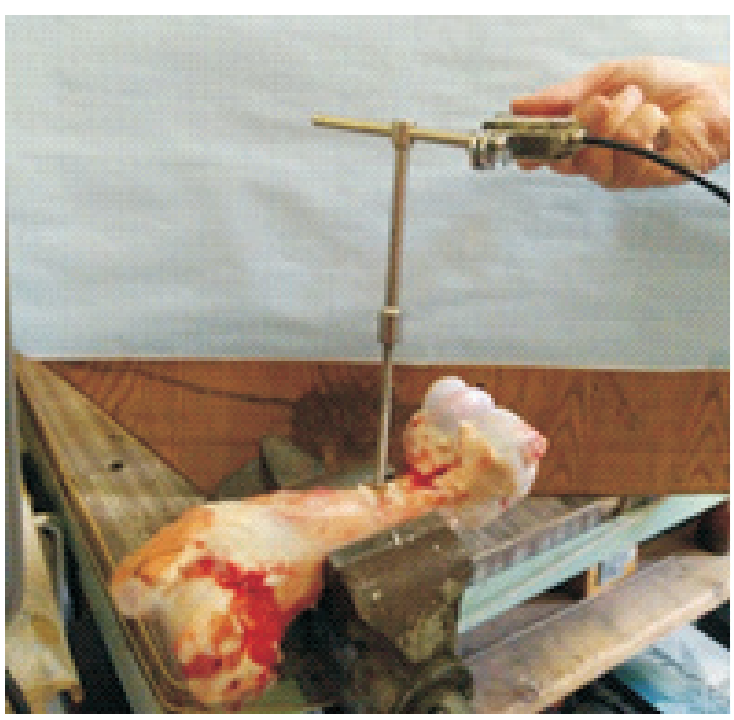

Fig. 13. An experimental study of the unscrewing moment value, when a rod is screwed into the bone tissue

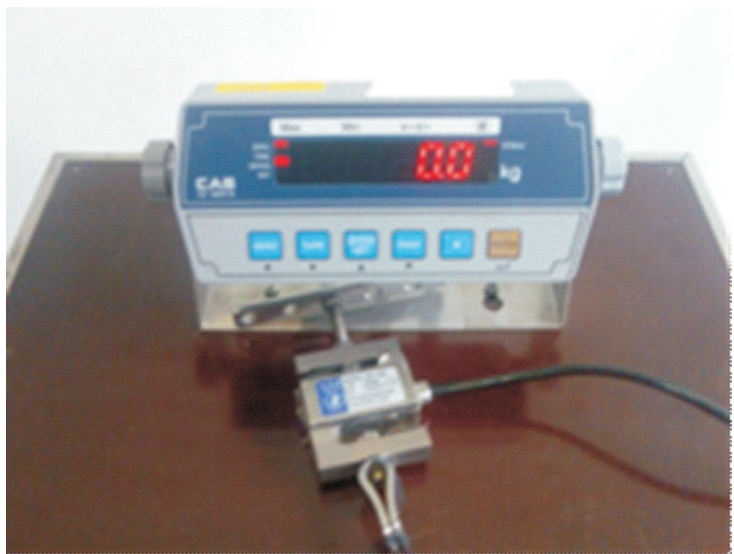

Fig. 14. The device for registering the value of loading with a tensometric sensor

According to the results of our experimental study the mean value of the unscrewing moment was $3.3 \pm 0.32 \mathrm{Nm}$. As it can be seen, the main factors that produce their effect on the forces, required for unscrewing a threaded connection,
Table 2. The values of the unscrewing moment for a rod, which is screwed into the diaphyseal portion of the hip bone of a pig

\begin{tabular}{|c|c|c|c|}
\hline \multirow{2}{*}{ No. of test } & \multicolumn{3}{|c|}{ Unscrewing moment Munscr, Nm } \\
\cline { 2 - 2 } & Munscr & $\mathrm{M} \pm \mathrm{SD}$ & min $\div \max$ \\
\hline 1 & 2.80 & \multirow{3}{*}{$3.3 \pm 0.32$} & $2.80 \div 3.60$ \\
\hline 2 & 3.50 & & \\
\hline 3 & 3.40 & & \\
\hline 4 & 3.20 & & \\
\hline 5 & 3.60 & & \\
\hline
\end{tabular}

are as follows: the moment of the previous tightening and the friction force on turns and edges of the thread. Consequently, lowering of the unscrewing moment is directly caused by a change of the friction force in turns and edges of the thread. One study [2] has examined the effect of vibration on the friction ratio and demonstrated that longitudinal vibration is its major cause. The conditions for absence of slipping are as follows:

$$
\frac{2 M_{\text {вгв }}\left[\tan (\phi-\psi)+f_{T} \frac{d_{c p}}{d_{2}}\right]}{d_{2}\left[\tan (\phi+\psi)+f_{T} \frac{d_{c p}}{d_{2}}\right]}>m A \omega^{2}
$$

where $\mathrm{m}$ - rod weight, in our case $\mathrm{m}=20 \mathrm{~g}$;

$$
\text { A - vibration amplitude; }
$$$$
\omega \text { - vibration frequency. }
$$

Having transformed the equation (3), we can receive an equation for determining critical values of vibration frequency depending upon its amplitude:

$\omega<\sqrt{\frac{2 M_{\text {вгв }}\left[\tan (\phi-\psi)+f_{T} \frac{d_{c p}}{d_{2}}\right]}{m A d_{2}\left[\tan (\phi+\psi)+f_{T} \frac{d_{c p}}{d_{2}}\right]}}$

Let us insert the necessary values into the equation (4) and calculate critical values of vibration frequency for its amplitude in the range from $1.0 \mathrm{~mm}$ to $5.0 \mathrm{~mm}$ with the pitch of $0.5 \mathrm{~mm}$.
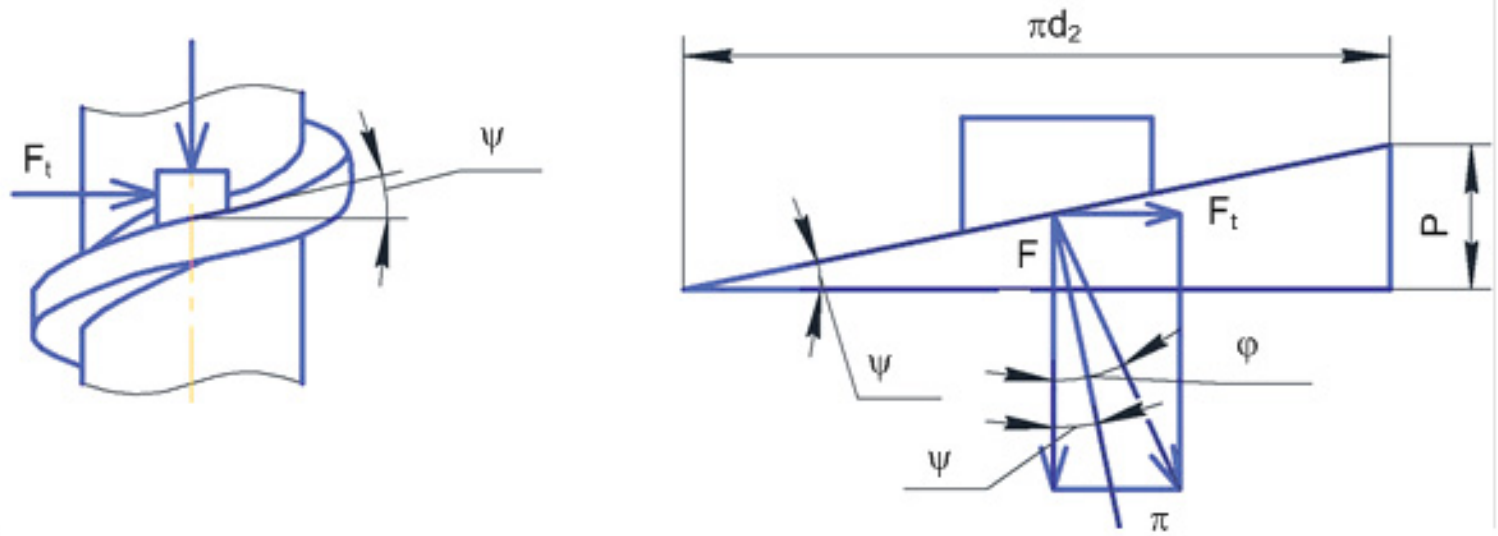

Fig. 15. Interacting forces in a threaded connection: where $\mathrm{Ft}$ - circumferential driving force; $\mathrm{F}$ - axial force on a screw; $\psi$ - lead angle; $\phi$ - friction angle; $\mathrm{d} 2$ - pitch diameter; $\mathrm{P}$ - thread pitch 
Results of the calculations are presented in Table 3.

Table 3. Critical values of vibration frequency from its amplitude for unscrewing a rod from the bone

\begin{tabular}{|c|c|}
\hline Amplitude, $\mathrm{mm}$ & Frequency, $\mathrm{Hz}$ \\
\hline 0 & 681 \\
\hline 0.5 & 305 \\
\hline 1.0 & 215 \\
\hline 1.5 & 176 \\
\hline 2.0 & 152 \\
\hline 2.5 & 136 \\
\hline 3.0 & 124 \\
\hline 3.5 & 115 \\
\hline 4.0 & 108 \\
\hline 4.5 & 102 \\
\hline 5.0 & 96 \\
\hline
\end{tabular}

A better visualization of critical values of vibration frequency from its amplitude, for rod unscrewing from the bone is possible with help of a graph given in Fig. 16.
Table 4. Values of unscrewing

of rods under vibrational effect

\begin{tabular}{|c|c|c|}
\hline \multirow{2}{*}{ SI. No. } & \multicolumn{2}{|c|}{ Values of unscrewing of rods, $\mu \mathrm{m}$} \\
\cline { 2 - 3 } & $\begin{array}{c}\text { Unidirectional } \\
\text { threads }\end{array}$ & $\begin{array}{c}\text { Differently } \\
\text { directed threads }\end{array}$ \\
\hline 1 & 713 & 0 \\
\hline 2 & 823 & 0 \\
\hline 3 & 936 & 0 \\
\hline $\mathrm{M} \pm \mathrm{SD}$ & $824 \pm 112$ & 0 \\
\hline min $\div \max$ & $713 \div 936$ & 0 \\
\hline
\end{tabular}

the device that had rods with a differently directed thread they did not unscrew at all $(0 \mu \mathrm{m})$. We explain it by the fact that the presence of barconnected screws with a differently directed thread creates a reciprocally interlocking structure, which counteracts self-unscrewing.

The stability of threaded connections is based on the presence of the friction force in the thread plane that in its turn depends upon the pressing force of the centralizer. Vibration is one of unfavorable factors for stability of threaded connections. Vibration causes microdisplacements

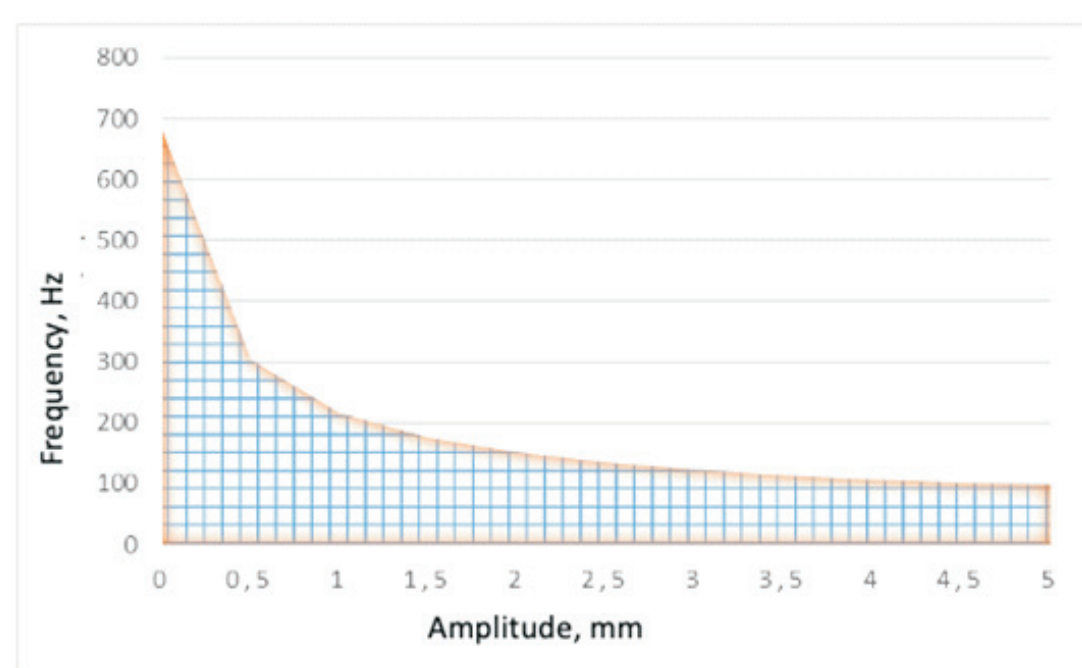

Fig. 16. Diagram of vibration frequency dependence upon its amplitude, which is critical for unscrewing a rod from the bone tissue

The above graph vividly demonstrates that the region above the shaded area is especially dangerous from the viewpoint of possible selfunscrewing of rods.

Table 4 contains the results of testing of the pelvic bones of a pig for vibrational effect; the above bones were connected with an external fixation device in variants with rods having unidirectional and differently directed threads.

As a result of the conducted studies it has been revealed that screws with a unidirectional thread are less resistant to cyclic alternate loads. The mean value of screw unscrewing was $824 \pm 112 \mu \mathrm{m}$. In of the centrator with a resultant reduction of the friction force in some cases down to zero. The studies of the unscrewing moment value have shown that the rod used for fixing the pelvic bones creates a sufficient pressing force, but with regard for the structure mass tends to its reduction under the effect of low-frequency mechanical vibrations. This fact was confirmed by the results of tests on a shaker device. One of the methods for counteracting a negative effect of vibration waves on threaded connections consists in creating an additional pressing force by using spring washers, plastic or silicone sealants, etc. Another method involves blocking of a threaded connection, for example with help of 
a check nut. In our case the blocking was achieved by using rods with differently directed threads, which provide self-locking of the rods. Experimental studies on a shaker device completely confirmed the effectiveness of such an approach.

\section{Conclusions}

We believe that in order to increase the stability and reliability of pelvic fixation with EFD it is necessary to use a left-handed thread for the left rod, thereby making it possible to avoid loosening of its fixation in the bone, since the "behavior" of the left rod will be similar to that of the right one.

A change in the thread direction does not lead to redistribution of SSS and change in the moment values, but directions of the action of the moments of force for the left rod will correspond to the direction of its screwing both in the left- and right-sided one-support position, i.e. both in standing and walking.
Bar-connected rods with a differently directed thread create a reciprocally interlocking structure, which counteracts self-unscrewing. Such a structure significantly increases the strength of connection of an external fixation device with the pelvic bone and creates conditions for an effective use of the technique of CPM in rehabilitation of patients with unstable pelvic fractures.

\section{Acknowledgments}

The authors would like to express their gratitude to laboratory scientists of the State Institution "Sytenko Institute of Spine and Joint Pathology of the National Academy of Medical Sciences of Ukraine" Yaresko A.V. and Karpinska Ye.D. for their consulting and technical assistance in conducting these researches.

\section{Conflict of interests}

The authors of the article declare no conflict of interests.

\section{References}

1. Osterhoff, G., Tiziani, S., Ferguson, S. J., Spreiter, G., Scheyerer, M. J., Spinas, G. L., ... Werner, C. M. (2014). Mechanical testing of a device for subcutaneous internal anterior pelvic ring fixation versus external pelvic ring fixation. BMC Musculoskeletal Disorders, 15, 111. doi:10.1186/14712474-15-111

2. Lei, J., Dong, P., Li, Z., Zhu, F., Wang, Z., \& Cai, X. (2017). Biomechanical analysis of the fixation systems for anterior column and posterior hemi-transverse acetabular fractures. Acta Orthopaedica et Traumatologica Turcica, 51(3), 248-253. doi:10.1016/j.aott.2017.02.003

3 Zienkiewicz, O. C., \& Taylo, R. L. (2005). The Finite Element Method for Solid and Structural Mechanics. Butterworth-Heinemann.

4. Lee, C. H., Hsu, C. C., \& Huang, P. Y. (2017). Biomechanical study of different fixation techniques for the treatment of sacroiliac joint injuries using finite element analyses and biomechanical tests. Computers in Biology and Medicine, 87, 250-257. doi:10.1016/j.compbiomed.2017.06.007

5. Ding, S., Chen, F., Huang, J., Zhang, G., Wang, F., ... Ruan, Z. (2020). Modified pedicle screwrod versus anterior subcutaneous internal pelvic fixation for unstable pelvic anterior ring fracture: A retrospective study and finite element analysis. Orthopedic Clinical Research. doi: 10.21203/rs.3.rs$16488 / \mathrm{v} 1$.

6. Jhou, S. Y., Shih, K. S., Huang, P. S., Lin, F. Y., \& Hsu, C. C. (2019). Biomechanical analysis of different surgical strategies for the treatment of rotationally unstable pelvic fracture using finite element method. Journal of Mechanics in Medicine and Biology, 19(1), 1940015. doi:10.1142/S0219519419400153

7. Li, L., Lu, J., Yang, L., Zhang, K., Jin, J., Sun, G., Wang, X., \& Jiang, Q. (2019). Stability evaluation of anterior external fixation in patient with unstable pelvic ring fracture: a finite element analysis. Annals of Translational Medicine, 7(14), 303. doi:10.21037/atm.2019.05.65

8. Chen, H., Wu, L., Zheng, R., Liu, Y., Li, Y., \& Ding, Z. (2013). Parallel analysis of finite element model controlled trial and retrospective case control study on percutaneous internal fixation for vertical sacral fractures. BMC Musculoskeletal Disorders, 14, 217. doi:10.1186/1471-2474-14-217.

9. Liu, L., Fan, S., Chen, Y., Peng, Y., Wen, X., Zeng, D., Song, H., \& Jin, D. (2020). Biomechanics of Anterior Ring Internal Fixation Combined with Sacroiliac Screw Fixation for Tile C3 Pelvic Fractures. Medical Science Monitor : International Medical Journal of Experimental and Clinical Research, 26, e915886. doi:10.12659/MSM.915886

10. Shan, T., Anlin, L., Mingming, Y., Haitao, Y., Anwei, Z., \& Shichang, G. (2020). Anterior supraacetabular external fixation for tile $\mathrm{C} 1$ pelvic fractures: a digital anatomical study and a finite element analysis. European Journal of Trauma and Emergency Surgery, 10.1007/s00068-020-01517-8. 
11. Shim, V., Gather, A., Hoch, A., Schreiber, D., Grunert, R., Peldschus, S., Josten, C., \& Bohme, J. (2017). Development of a Patient-Specific Finite Element Model for Predicting Implant Failure in Pelvic Ring Fracture Fixation. Computational and mathematical methods in medicine, 2017, 9403821. doi:10.1155/ 2017/9403821

12. Bone mechanics handbook (2001). S. C. Cowin (Ed.). CRC Press Reference.

13. Vidal-Lesso, A., Ledesma-Orozco, E., Daza-Benitez, L., |\& Lesso-Arroyo, R. (2014). Mechanical Characterization of Femoral Cartilage Under Unicompartimental Osteoarthritis. Ingenieria Mecanica Tecnologia Y Desarrollo, 4(6), 239-246.

14. Savio, L. Y., \& Woo, S. D. (2006). Abramowitch, Robert Kilger, Rui Liang. Biomechanics of knee ligaments: injury, healing, and repair. Journal of Biomechanics, 39, 1-20. doi:10.1016/j.jbiomech.2004.10.025

15. Modenese, L., Phillips, A. T., \& Bull, A. M. (2011). An open source lower limb model: Hip joint validation. Journal of Biomechanics, 44(12), 2185-2193. doi: 10.1016/j.jbiomech.2011.06.019

16. Karpinskiy, M. Iu., Zubatii, S. S., Lavinskii, D. V., \& Fomin, G. G. (2000). Matematicheskoye issledovaniye mekhanicheskikh kolebatel'nykh svoystv dlinnykh kostey [Mathematical study of mechanical vibrational properties of long bones]. Medicina і и ..., (1), 47-50.

17. Serdiuk, A. I., Miteleva, Z. M., Kas'yanov, A. I., Mon'ko, O. N., \& Karpinskiy, M. Iu. (1994). Razrabotka, sozdaniye i issledovaniye upravlyayemogo vibromassazhnogo ustroystva [Development, creation and research of a controlled vibration massage device]. Proceedings 45th Conference of Polava ISI, Poltava, 214.

18. Aleksandrov, A. V., Potapov, V. D., \& Derzhavin, B. P. (2000). Soprotivleniye materialov [Strength of materials]. Moscow: Vysshaya shkola.

19. Birger, I. A., \& Iosilevich, G. B. (1990). Rez'bovyye i flantsevyye soyedineniya [Threaded and flange connections.]. Moscow: Mashinostroyeniye.

20. Blekhman, I. I., Blekhman, L. I., Vasil'kov, V. B., Ivanov, K. S., \& Yakimova, K. S. (2012). Ob iznose oborudovaniya $\mathrm{v}$ usloviyakh vibratsii i udarnykh nagruzok [Wear and tear of machine parts affected by vibration and percussive impacts]. Vestnik nauchno-tekhnicheskogo razvitiya, (11), 3-14. Retnrived from http://www.vntr.ru/ftpgetfile.php?id=643

21. Nasledov, A. (2011). SPSS 19: professional'nyy statisticheskiy analiz dannykh [SPSS 19: Professional Statistical Analysis of Data]. Saint Petersburg: Peter.

Received: 03-Dec-2020

Accepted: 15-Mar-2021 